\title{
Aesthetics and Border Lines
}

\author{
"Design" as a Liminal Case
}

Morten Kyndrup

\section{0}

Aesthetics, of course, is a discipline, but "aesthetics", "the aesthetic", and "aestheticity" are also concepts. The question of the border lines of aesthetics thus necessarily implies one's general approach to the status of concepts. I shall therefore briefly sketch out some more general pre-conditions which may be necessary in order to understand my approach to these problems.

First of all: Concepts are names. We use concepts to name phenomena and substances we meet in our reality. Lots of problems and confusions can be identified in the business of naming. We have, on the one hand, the case of the same substance with different names (called synonymy) and, on the other, we have the opposite problem of the same name designating different substances - the case of so-called polysemy. We have proper names designating in principle one and only one phenomenon, so-called rigid designators (which was Kripke's term) and we have appellatives, names for groups or types of phenomena sharing certain properties, for instance "chair", "house", or "conference". Consequently, we of course also have blurred or changing border lines between categories, both in general and pertaining to singular cases.

At a general level, I would characterize my approach as conceptualist within the framework of what has been called "semiotic realism". This approach is nominalist in the sense that it emphasizes the difference between our naming and the reality it refers to. At the same time, it is a realist one in the sense that it considers the naming system (language, the concepts) as objectively existing, that is: part of the reality outside us as individuals.

I am not here going to recall the whole historical discussion of universals in philosophy. Sufficient in this connection is to state the fact that the interesting issue in this discussion is not the names as such: Interesting are the substances they designate, "reality". In principle, you can change 
a name just by decision. You cannot change the world by decision. To the extent concepts have become integrate parts of our naming system, they form part of our reality as well, and thus become subjectively unchangeable. This does not mean that concepts and their references do not change. Indeed they do. Everything in the world of humans is subject to change. The cadences of change, however, are different. Different cadences of change in different areas co-exist and interfere mutually into their respective semiotic domains: the properties of human nature in a biological sense; western civilisation; modernity's discursive distinction between areas; the division of labour between men and women; the status and extension of judgements in everyday life; the width of the leg on blue jeans, etc.

Although, of course, all kinds of conflations, cross-overs, and misunderstandings, both subjectively and objectively, are indeed notorious in this ever changing semantic landscape, it is a core part of my strategic approach to any discussion of conceptual delimitations that no confusions or ambiguities in this landscape are coincidental. I.e., also obvious contradictions in terms have their explanations, form part of some kind of rationality - or at least have done so earlier on. Another fact - perhaps banal but still important to keep in mind in this connection - is that concepts without limits are useless and at the bottom line literally meaningless. In fact, the most interesting part of concepts may indeed be their border line problems. Border line problems pertaining to concepts are not some kind of disease which should be cured. Semantic liminality and ambiguity is the very source of conceptual life.

\section{I}

But back to aesthetics. The history of aesthetics has indeed been dominated by liminality problems. This is completely natural, and even more so given the fact that aesthetics is a "new" concept forming part of modernity's differentiation processes, transforming its heritage of traditional philosophy of beauty into the upcoming creation of discursive differences.

The fact that the existence of border line problems to the concept of aesthetics throughout its lifetime have been natural and explainable does not imply, however, that all of these problems have contributed equally productively to the development of conceptual clarity. I shall start out by calling attention to two interconnected areas of semantic liminality conflict pertaining to aesthetics - both of which are natural parts of the concept's process of identifying its own semantic position, but which over time have become decisively counter-productive in certain respects. The 
first one pertains to the territory of aesthetics, the second one to the modality of the discipline's approach.

The territorial one concerns aesthetics' relationship to art - in particular what has been called the "marriage" between art and the aesthetic formed by Romanticism in the early history of the concept of aesthetics. This marriage, which I have dealt with elsewhere, apparently marked an enormous expansion of the aesthetic, linking it to art's seemingly transdiscursive auratic sphere. But this was also an expansion, as it has become increasingly clear over the last half century, which constituted a kind of prison or iron curtain for aesthetics, keeping it captured behind the palisades of art's autonomy, delimiting it to this conceptual partnership with art. Among other things, the consequence of this partnership was that aesthetics was bound to share arts' conflictual relationship to theory and Wissenschaft.

This consequence is closely related to the other problem I want to underline here, the modal one. This problem consists in the fact that aesthetics as a discipline to a large extent has considered it its task to pronounce aesthetic judgements. Once again, historically this task implied an elevation of the discipline's status. By linking itself institutionally to the objectbound aspect of the aesthetic judgement, aesthetics gained a surplus of authority and enhanced an elevation of status in relation to everyday-life. But in the long run, this very same privilege would undermine aesthetics' authority as a contributor to objective (i.e.: intended value-free, unbiased) scientific knowledge about the phenomenon of aesthetic value. The privilege of expressing preferences concerning aesthetic value furnished aesthetics as a discipline with a touch of subjectivity which was to become a decisive obstacle in the recognition of its status as value-free knowledge or science. This systematic confusion of discipline and object for long kept aesthetics in a conceptual childhood of some sorts. The fact that aesthetic relations are value based and value producing and have the aesthetic judgement as their core activity does by no means imply that the discipline studying these values and judgements should itself pronounce that kind of judgements, or for that matter, even if so, should possess any kind of privilege concerning the direction and content of such judgements.

\section{II}

A third liminality problematic, reappearing again and again in the history of the concept of aesthetics, is dealing with the question of where aesthetic quality is to be found or produced: In the object or in the subject. 
This problem has been dealt with thoroughly and it has frequently led to approaches resembling un-intermediated double strategies. Consider for example David Hume's On the Standard of Taste (1757) arguing in favour of general standards and yet rejecting the beauty as a property of the object. Or, similarly, Denis Diderot's distinction in the Encyclopédie between "beau réel" and "beau aperçu", real and experienced beauty (1752). This indeed is a long story. Its apparent aporias is anything but counterproductive since this problematic touches upon the substantial part of what the aesthetic is about. As has become increasingly clear, aesthetic value is neither exclusively subject-bound nor object-bound. Aesthetic value is subjective, but it is strictly referring to an object. I.e.: Aesthetic value is relational and singular. In his book, La relation esthétique, Gérard Genette phrases it that the adjective "aesthetic" is "not dispositional but resultative". And he continues, "it is not the object that makes the relation aesthetic, it is the relation that makes the object aesthetic" (op.cit. p. 18).

If this is an adequate understanding of the nature of aesthetic value, it raises fundamental questions to the scholarly approach performed by aesthetics. If, one might ask, aesthetic value is always in this sense singular, would that not reduce aesthetics to a sub-discipline of sociology (i.e. mapping empirically existing judgements of taste) or at least delimit its activities to a study of the very mechanism of the aesthetic judgement? Again, the answer will be yes and no. We might illustrate the problem with a parallel: The case of traffic accidents. Traffic accidents are always singular events, happening in a specific configuration of time and space. In that sense, real knowledge about traffic accidents must be based on their sociology and on empirically founded insights into their mechanisms. But besides this, a third level of knowledge occurs. That is the one of analyzing and calculating potential risks of traffic accidents, based on the knowledge of traffic, of patterns of reaction, of technical properties of roads and of vehicles etc. Given this knowledge, one can analyze the probable physiognomy of a given potential traffic accident related to given times, places, and involved instances.

This, of course, may be a somewhat farfetched allegory. The purpose of it, however, is to emphasize the fact that, on the one hand, aesthetic relations indeed are singular and unique as such. On the other hand, objectual (and situational) properties may be analyzed and categorized in regard to their ability to produce distinctive conditions for specific aesthetic value production. In particular, this may be analyzed by using the core concepts of reception theory, of so-called model senders and receivers. We seemingly perceive all objects with which we enter into aesthetic rela- 
tions, as being in a specific sense addressed to us. Many of them, artworks for instance, actually are addressed to us. By sorting out the instances of embedded or implied senders/receivers, an operation of analyzing virtual aesthetic values of objects becomes manageable. Thereby, it becomes possible to operate with properties like implied intentional aesthetic value as an also intensional (with an s) property of a given artefact.

\section{III}

Now let us return to the issue of limits. Given a status of the aesthetic as "resultative", there may indeed exist such a thing as a territory of aesthetic objects, that is, objects that have become aesthetic. The above mentioned implied aesthetic relationality might make it possible to define yet another territory of the aesthetic, perhaps as a region or a zone of the former, and either way in some sense connected to it.

Decisive, however, is the fact that these territories obviously do not form part of what in a mathematical sense is called division in classes - or of the way we usually understand divisions of land in territories, for instance nations. This is when any piece of land belongs to one and only one territory. In the case of the aesthetic, on the other hand, the border lines of these territories refer to only one out of many possible logics of division. They are in other words not exhaustive. They are not even stable. This also holds true for a territorial division based on a distinction between types of relationality. Divisions based on other kinds of relationality would thus result in alternative territories with other border lines.

In short, "aesthetic" is not an exhaustive predicate. It is not a stable, objectual quality which identifies a given object and makes it irreversibly belong to a certain class of objects. "Aesthetic" should rather be defined as a "modelling operation" as it has recently been proposed by Wolfgang Iser following a concept of W. C. Wimsatt.

Now, a brief look at the case of design may be illustrative as to what this means.

When we perceive a given object as a piece of design, we do, on the one hand, let it stand out as something singular, and we acknowledge its objectual form and its distinctive appearance as if this very form was addressing exactly us, about to perceive this singular form as good or bad. We clearly establish an aesthetic relation to this object, pronouncing a judgement of taste which is singular and personal. Interesting here (as compared to for instance artworks) is the fact that a piece of design may obviously be the result of a mass production, but that this does not diminish its unique value or status as a singular, desirable object for us. 
On the other hand, this approach to a given object, perceiving its form as something addressing us and thus forming the basis of a judgment of taste is obviously only one possible approach among several others. We might approach a desk lamp, a car, or a laptop from an aesthetic point of view, but we might also approach and discuss each of them within other categories, such as functional properties, mechanical quality, price etc. The point here, once again, is that these different properties or classes of objectual qualities each correspond to or match a specific approach (or modelling operation, if you will), and that, although these approaches all refer to the same object, they have nothing to do with each other in the sense that they could represent a division in territories. We do actually possess the ability to switch from an aesthetic approach to an alternative, for instance a use value-orientated one in any given situation, and of course we may combine the result of our judgements and analyses at different levels, but you cannot find such a thing as a border line zone within the object between its (implied or realized) aesthetic qualities and its other layers or qualitative properties.

In the case of design, we find it spontaneously unproblematic to switch between modes of approach or modelling operation, and we would never dream of making the assessment that the aesthetic qualities of a given object were exhaustively representative for its properties as a whole. We might accept to drive in a beautifully designed car with a lousy mechanical quality or to sit in a terrific chair that hurts our back - but we would know distinctively what we did. Or put otherwise: We would know that other qualities are naturally to be found in any given object than the one represented by the aesthetic approach.

\section{IV}

My point, of course, is that this distinction between qualitative approaches and consequently between functional objectual qualities remains true also in the case of artworks. Artworks may be perceived as aesthetic objects and thus qualified and judged as such. But they may also be perceived in other ways, at other levels, through other channels, for instance in terms of sources of historical or conceptual knowledge about civilization, about themselves, about their originator, about specific events etc. In other words, art theory (and art history in a wider sense) is something different from aesthetic theory. It is true, of course, that the historical process of elaborating Modernity's aesthetic relationality is closely and delicately connected to the possibilities offered by autonomous art. The confusion of the boundaries of art and those of the aesthetic and consequently of 
"philosophy of art" and "aesthetics" are thus indeed historically understandable and explainable. But this fact does not make the confusion less counterproductive from today's perspective. Its counter-productivity is, as sketched out here, not least due to the fact that the confusion of territories and boundaries does not only pertain to a misreading of specific topographical positions, but rather to a basic difference in the very conceptual shape or mode of the delimitation mechanisms respectively.

To conclude about the delimitations of "the aesthetic" and thus of aesthetics - and I should add that the argument here is an extremely condensed version of my book on the aesthetic relation which has been published in Danish earlier this year (2008): The limits of the aesthetic as a phenomenon are complex, transitory, and basically inherent in the objects, taking the shape of a dispositional or virtual property. Aesthetic qualities might be characterized as belonging to an "immanence plane" un plan d'immanence (which is Deleuze/Guattari's concept from Qu'est-ce que la Philosophie).

So "the aesthetic" deals with a specific kind of relations, pertaining in principle to any objectual, situational entity taking up an objectual position. I.e., we live in a world of immense quantities of actual and virtual aesthetic objects (plus quite a few historically proven, having entered the archives of aesthetic relations). The quality of being aesthetic, however, is not exhaustive, it is generally reversible, and it is certainly not exclusive in comparison to other relational and objectual qualities.

Aesthetics, being the discipline studying these aesthetic relations, should obey general rules of probability, argument, and truth proving like any other branch of Wissenschaft in a continental sense. The discipline of aesthetics consequently possesses no privilege to pronounce judgments of taste. To adapt, to confirm, and to realise this decisive distinction between the nature of the object of study and the nature of the scholarly approach might indeed constitute a becoming-modern of aesthetics. Finally, one might add.

\section{References}

Deleuze, Gilles and Félix Guattari. Qu'est-ce-que la philosophie? Paris: Minuit, 1991.

Diderot, Denis. "Recherches philosophiques sur l'origine de la nature et du beau"

[1752], in Euvres esthétiques de Diderot, éd. Paul Vernière. Paris: Garnier, 1968.

Genette, Gérard. L'œuvre de l'art. 2. La relation esthétique Paris: Seuil ,1997. Eng.

transl.: The Aesthetic Relation. Ithaca: Cornell UP, 1999.

Hume, David. "Of the Standard of Taste", in Essays Moral, Political, and Literary, 
Aesthetics and Border Lines

vol. I, edited by T.H. Green and T.H. Grose, 266-284. London, 1875.

Iser, Wolfgang. "Von der Gegenwärtigkeit des Ästhetischen", in Dimensionen ästhetischer Erfahrung, hsrg. von Joachim Küpper und Christoph Menke.

Frankfurt: Suhrkamp, 2003. Iser quotes W.C.Wimsatt: "Generative Entrenchment and the Developmental Systems Approach to Evolutionary Processes", ms. 2000.

Kripke, Saul. "Naming and Necessity", in Semantics of Natural Language, edited by G. Harman and D. Davidson, 253-355. Dordrecht: Reidel, 1972.

Kyndrup, Morten. "Art Theory versus Aesthetics. The Story of a Marriage and its Decline and Fall". In Perspectives on Aesthetics, Art and Culture, edited by Claes Entzenberg and Simo Säätela. Stockholm: Thales, 2005.

Kyndrup, Morten. Den cestetiske relation. Copenhagen: Gyldendal, 2008. 